\title{
Bacterial diversity in rhizosphere soil from Antarctic vascular plants of Admiralty Bay, maritime Antarctica
}

\author{
Lia CRS Teixeira ${ }^{1}$, Raquel S Peixoto ${ }^{1}$, Juliano C Cury ${ }^{1}$, Woo Jun Sul ${ }^{2}$, Vivian H Pellizari ${ }^{3}$, \\ James Tiedje ${ }^{2}$ and Alexandre S Rosado ${ }^{1}$ \\ ${ }^{1}$ Laboratório de Ecologia Microbiana Molecular, Departamento de Microbiologia Geral, Instituto de \\ Microbiologia Professor Paulo de Góes, Universidade Federal do Rio de Janeiro, Rio de Janeiro, Brazil; \\ ${ }^{2}$ Center for Microbial Ecology, Michigan State University, East Lansing, MI, USA and ${ }^{3}$ Instituto \\ Oceanografico, Universidade de São Paulo, São Paulo, Brazil
}

\begin{abstract}
The Antarctic is a pristine environment that contributes to the maintenance of the global climate equilibrium. The harsh conditions of this habitat are fundamental to selecting those organisms able to survive in such an extreme habitat and able to support the relatively simple ecosystems. The DNA of the microbial community associated with the rhizospheres of Deschampsia antarctica Desv (Poaceae) and Colobanthus quitensis (Kunth) Bartl (Caryophyllaceae), the only two native vascular plants that are found in Antarctic ecosystems, was evaluated using a 16S rRNA multiplex 454 pyrosequencing approach. This analysis revealed similar patterns of bacterial diversity between the two plant species from different locations, arguing against the hypothesis that there would be differences between the rhizosphere communities of different plants. Furthermore, the phylum distribution presented a peculiar pattern, with a bacterial community structure different from those reported of many other soils. Firmicutes was the most abundant phylum in almost all the analyzed samples, and there were high levels of anaerobic representatives. Also, some phyla that are dominant in most temperate and tropical soils, such as Acidobacteria, were rarely found in the analyzed samples. Analyzing all the sample libraries together, the predominant genera found were Bifidobacterium (phylum Actinobacteria), Arcobacter (phylum Proteobacteria) and Faecalibacterium (phylum Firmicutes). To the best of our knowledge, this is the first major bacterial sequencing effort of this kind of soil, and it revealed more than expected diversity within these rhizospheres of both maritime Antarctica vascular plants in Admiralty Bay, King George Island, which is part of the South Shetlands archipelago.

The ISME Journal (2010) 4, 989-1001; doi:10.1038/ismej.2010.35; published online 1 April 2010
\end{abstract}

Subject Category: microbial population and community ecology

Keywords: Antarctica soil; rhizosphere; Colobanthus quitensis; Deschampsia antarctica; microbial diversity; pyrosequencing

\section{Introduction}

The Antarctic environment is affected by many variable conditions, including low thermal capacity of the substratum, frequent freeze-thaw and wetdry cycles, low and transient precipitation, low humidity, rapid drainage and limited organic nutrients (Wynn-Williams, 1990). The harsh conditions of the Antarctic environment support only relatively simple ecosystems, with very low complexity food-web structures in the most extreme Antarctic habitats (Wall and Virginia, 1999).

Correspondence: AS Rosado, Laboratório de Ecologia Microbiana Molecular, Instituto de Microbiologia Professor Paulo de Góes, Universidade Federal do Rio de Janeiro, Av Carlos Chagas Filho 373, Rio de Janeiro, RJ 21941902, Brazil.

E-mail: asrosado@micro.ufrj.br

Received 8 October 2009; revised 8 February 2010; accepted 17 February 2010; published online 1 April 2010
The terrestrial environment of the Antarctic Peninsula is dynamic, variable and a region of extreme habitats. However, this region does not possess the characteristics found in the central region of the Antarctic continent (Convey, 2001), as it receives materials directly from sea spray as well as from the birds and mammals that feed in the sea. The climate of the peninsula is strongly influenced by low-pressure areas. Indeed, despite the low amount of rainfall, the precipitation rate exceeds the evaporation rate, and the soils have a relatively high moisture content, which provides favorable conditions for microbial growth (Campbell and Claridge, 1987). The general climate data show that the mean annual temperature is relatively stable in the area of Admiralty Bay (located at King George Island) at about $-1.8^{\circ} \mathrm{C}$. During the short period of summer (December to March), there are major changes in the dynamics and relationships between 
the environment and the organisms that live there (Campbell and Claridge, 1987).

Microorganisms are the dominant biomass component of Antarctic ecosystems (Wynn-Williams, 1996; Pointing et al., 2009). This dominance of microorganisms results in a relatively simplified system sensitive to perturbations (Yergeau and Kowalchuk, 2008). However, the microbial diversity in Antarctic soil has not been well documented, and it is not known how disturbances in this diversity could affect this ecosystem and other related ecosystems.

In Antarctica, the native Magnoliophyta are represented only by Deschampsia antarctica Desv (Poaceae), known as Antarctic hair grass, and Colobanthus quitensis (Kunth) BartI (Caryophyllaceae), also known as Antarctic pearlwort. Because the vegetative cover usually influences the microbial diversity of soil, understanding the microbial diversity in the maritime Antarctica region requires scientists to collect information about the microbial diversity associated with the rhizosphere of the only two autochthonous vascular plants.

Yergeau and Kowalchuk (2008) showed in microcosm experiments that changes in the vegetative cover and the frequency of freeze-thaw cycles generated by global warming could strongly affect the microbial communities of Antarctic soil. They also showed that the vegetative cover influenced many microbial responses, further strengthening the potential of global warming to affect soil microorganisms. Other researchers had previously hypothesized that indirect effects, such as vegetation distribution and other biophysical soil properties, are more relevant than direct effects of global warming (Vishniac, 1993; Panikov, 1999). Now that an increase of $1.7^{\circ} \mathrm{C}$ at the King George Islands area has been reported in the past 50 years (Beyer, 2000), it is important to know as much as possible about the microbial diversity of this region to predict the possible impact of global climate changes, and the development of molecular tools is now improving Antarctic research (Peck et al., 2005).

Recently, high-throughput sequencing using sequencing-by-synthesis technology (454 pyrosequencing) was introduced as a new approach capable of better revealing the taxonomic diversity within extant microbial communities (Sogin et al., 2006; Roesch et al., 2007; Acosta-Martinez et al., 2008). Partial ribosomal amplification before pyrosequencing is an approach that can be used to describe precisely microbial communities in environmental samples (Binladen et al., 2007; Acosta-Martinez et al., 2008). Despite the inherent bias in PCR and all molecular methods (Dowd et al., 2008), which are the same for all analyzed samples, it is interesting to combine the selectivity of primer-based PCR with high-throughput sequencing technology. Also, the use of the bacterial tag-encoded FLX amplicon pyrosequencing method allows for mixed samples to be run on the same sequencing run and later binned
(Binladen et al., 2007; Acosta-Martinez et al., 2008; Dowd et al., 2008).

In our view, Antarctica is a pristine environment that is essential to the Earth, and all studies concerning its biological diversity should be considered a priority. To the best of our knowledge, no studies have been conducted on the bacterial diversity in the rhizospheres of maritime Antarctica vascular plants. In this study, we used highthroughput sequencing and DNA fingerprinting (denaturing gradient gel electrophoresis, DGGE) to assess the diversity and composition of the bacterial communities associated with the rhizospheres of the two vascular plants (D. antarctica Desv (Poaceae) and C. quitensis (Kunth) BartI (Caryophyllaceae)) found in different sites in Maritime Antarctica.

\section{Materials and methods}

Sampling site and DNA extraction

The study was carried out at the Brazilian Antarctic Station, Estação Antártica Comandante Ferraz (EACF: $62^{\circ} 04^{\prime} \mathrm{S}, 58^{\circ} 21^{\prime} \mathrm{W}$ ), located in Martel Inlet, Admiralty Bay, King George Island, Antarctic Peninsula, which is part of the South Shetlands archipelago in Maritime Antarctica. It is a mediumsized research station with a population of 10-15 people during winter months (March to November) and about 50 people during austral summer months (November to March). During the austral summer of 2006-2007, D. antarctica and C. quitensis vascular plants were sampled near each other (about 0.5-1 m apart) in triplicate at three sites (A, Q and I; Figure 1; Table 1). In these areas, the soil was previously characterized as loamy sand (Simas et al., 2008). Point A was located inside an environmental protected area close to Arctowski Polish Station and next to a colony of Adelie penguins (Pygoscelis adeliae). No $C$. quitensis individuals were found during the collection. In section I, there were no penguin colonies present, but this section was used as a nesting site by local species of flying birds, possibly bringing a greater supply of organic material to the site. Point $Q$ was located in the vicinity of the EACF; thus there has been (and continues to be) an intense anthropogenic influence at this spot, which is not the case for the other sampling sites. Anthropogenic factors may have limited the presence of bird colonies; in this area, only a few skua (Catharacta sp.) nests were observed.

In each sample site, a $500 \mathrm{~g}$ soil aliquot was taken for physicochemical analyses. Each vascular plant sample was frozen $\left(-20^{\circ} \mathrm{C}\right)$ at the EACF. To access the bacterial communities associated with the rhizospheres of both vascular plants, we shook $5 \mathrm{~g}$ of the roots with aggregated soil in a saline solution $(\mathrm{NaCl}$ $0.85 \%$ ) for $1 \mathrm{~h}$. Then, $50 \mathrm{ml}$ of the supernatant was centrifuged for $10 \mathrm{~min}$ at 9000 r.p.m., and $0.5 \mathrm{~g}$ of the pellet soil was used for DNA extraction using the 

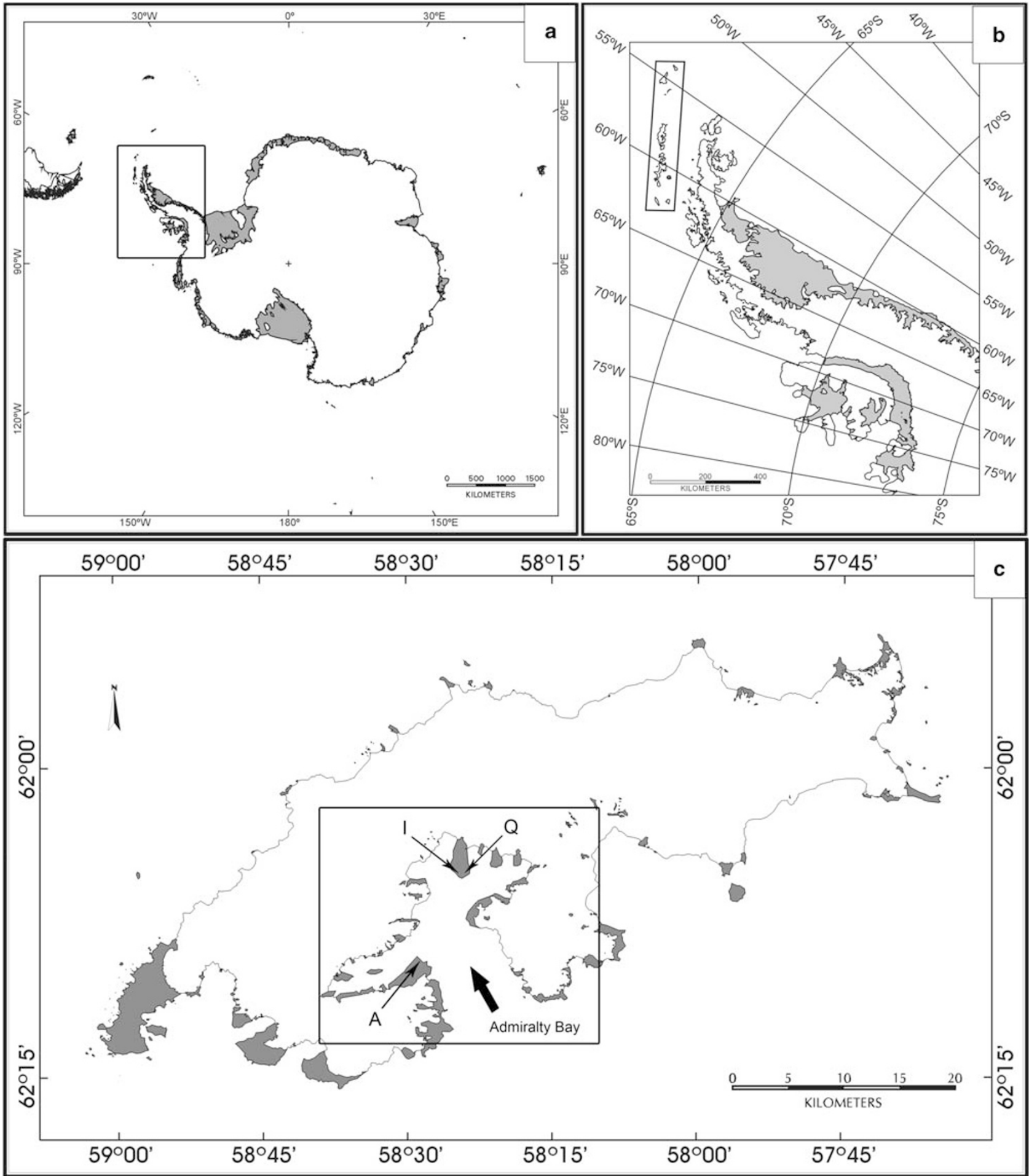

Figure 1 Map of the sample sites. (a) The Antarctic continent with the Antarctic Peninsula in relief. Areas in gray indicate ice shelves; (b) the Antarctic Peninsula and the South Shetland archipelago. Areas in gray indicate ice shelves; (c) King George Island, the biggest island in the South Shetland archipelago, with Admiralty Bay in relief. Sample sites are indicated by arrows. Here the areas that are not covered by ice are in gray. Adapted from Simões et al. (2004).

Fast DNA Spin Kit for soil (QBIOgene, Carlsbad, CA, USA) following the manufacturer's instructions. The extracted DNA was quantified using a Nanodrop ND-1000 spectrophotometer (Nanodrop Technologies,
Wilmington, DE, USA). The integrity of the DNA extracted from the soil was confirmed by electrophoresis in a $0.8 \%$ agarose gel with 0.5 TBE buffer (45 mM Tris-borate, 1 mM EDTA (pH 8.0)). 
Soil analysis

A total of 16 chemical variables were assessed in the soil analysis (aluminum, calcium, magnesium, phosphorous, potassium, sodium, organic carbon, sulfur, iron, copper, zinc, manganese, $\mathrm{Pb}, \mathrm{H}+\mathrm{Al}$, lead and $\mathrm{pH}$ ) using the protocols listed in EMBRAPA (1997), and the results are shown in Table 2. From each sampling point, five soil samples were collected and mixed to form a composite sample.

\section{S PCR}

For the PCR-DGGE assay, all the triplicate rhizosphere samples from the three sample sites were used (14 samples). A 16S rRNA gene fragment corresponding to nucleotide positions 968-1401 (Escherichia coli numbering) was amplified using the following universal bacterial primers: $968 \mathrm{f}\left(5^{\prime}\right.$-AAC GCG AAG AAC CTT AC-3'), which contains a 40 bp GC clamp (5'-CGC CCG CCG CGC GCG GCG GGC GGG GCG GGG GCA CGG GGG G-3') added to its 5-end making it suitable for DGGE, and 1401r (5'-CGG TGT GTA CAA GAC CC-3') (Heuer et al., 1997). The PCR mixture comprised $1 \mu$ l of DNA extracted from the rhizospheres of both vascular plants, $25 \mathrm{pmol}$ of universal primers, $5 \mu \mathrm{l}$ of $10 \times$ PCR buffer (Fermentas, Burlington, Ontario, Canada), $2.5 \mathrm{mM} \mathrm{MgCl}_{2}$, $2.5 \mathrm{U}$ of Taq DNA polymerase (Fermentas), $0.2 \mathrm{mM}$ of each deoxynucleoside triphosphate (Promega, Madison, WI, USA) and sterile filtered MilliQ water to a final volume of $50 \mu \mathrm{l}$. Negative controls consisted of sterile MilliQ water instead of sample.

Table 1 Samples description

\begin{tabular}{lll}
\hline Samples & Site & Cover plants \\
\hline IC1 & Brazilian Station 1-Ipanema & Colobanthus quitensis \\
IC2 & Brazilian Station 1-Ipanema & Colobanthus quitensis \\
ID1 & Brazilian Station 1-Ipanema & Deschampsia antarctica \\
ID2 & Brazilian Station 1-Ipanema & Deschampsia antarctica \\
QC7 & Brazilian Station 2-EACF & Colobanthus quitensis \\
QC8 & Brazilian Station 2-EACF & Colobanthus quitensis \\
QD7 & Brazilian Station 2-EACF & Deschampsia antarctica \\
QD9 & Brazilian Station 2-EACF & Deschampsia antarctica \\
AD10 & Arctowski Polish Station & Deschampsia antarctica \\
AD11 & Arctowski Polish Station & Deschampsia antarctica \\
& & \\
\hline
\end{tabular}

Abbreviation: EACF, Brazilian Antarctic Station Comandante Ferraz.
PCR amplification was performed in a DNA thermocycler (Mastercycler Personal; Eppendorf, Hamburg, Germany). The temperature profile included an initial denaturation step at $94^{\circ} \mathrm{C}$ for $2 \mathrm{~min}, 35$ cycles of a denaturation step at $94{ }^{\circ} \mathrm{C}$ for $1 \mathrm{~min}$, a primer annealing step at $55^{\circ} \mathrm{C}$ for $1 \mathrm{~min}$ and an extension step at $72{ }^{\circ} \mathrm{C}$ for $2 \mathrm{~min}$, followed by a final step of $72{ }^{\circ} \mathrm{C}$ for $10 \mathrm{~min}$. Before DGGE analysis, the presence of PCR products was confirmed by electrophoresis in a $1.2 \%$ agarose gel run at $80 \mathrm{~V}$ in Tris-borate-EDTA buffer. The gel was stained for $15 \mathrm{~min}$ with $0.5 \mu \mathrm{g} \mathrm{ml}^{-1}$ ethidium bromide and was viewed under short-wavelength ultraviolet light. A $100 \mathrm{bp}$ DNA ladder (Fermentas) served as the molecular size standard.

\section{DGGE assay}

Denaturing gradient gel electrophoresis of the PCR products generated with the 968f-GC/1401r primer set was performed using the Dcode universal mutation detection system (Bio-Rad Dcode, Richmond, VA, USA) according to Smalla et al. (2001). After electrophoresis, the gels were stained with SYBR Green I nucleic acid gel stain (Molecular Probes, Leiden, the Netherlands) for $40 \mathrm{~min}$ and were then scanned using a Storm PhosphorImager (Amersham Biosciences, Uppsala, Sweden). Analysis of the DGGE profiles was performed using the BioNumerics version 5.10 software package (Applied Maths, St-Martens-Latem, Belgium). A dendrogram was constructed using Pearson's correlation coefficients $(r)$ and cluster analysis was performed by the unweighted pair group method with average linkages.

\section{Pyrosequencing}

Partial bacterial 16S rRNA gene sequences were obtained from each replicate analysis of both rhizospheres using the coded-primer approach to multiplex pyrosequencing (Binladen et al., 2007). Replicates were randomly chosen. PCR amplification of the hypervariable V4 region of the $16 \mathrm{~S}$ rRNA gene was performed using the $8 \mathrm{bp}$ key-tagged eubacterial primers 563F and 802R (http:// wildpigeon.cme.msu.edu/pyro/help.jsp). PCR mixtures contained $1 \mu \mathrm{M}$ each primer (Integrated DNA

Table 2 Mean soil characteristics for surface soil cores $(0-5 \mathrm{~cm})$ collected in three sites at Admiralty Bay, King George Island

\begin{tabular}{|c|c|c|c|c|c|c|c|c|c|c|c|c|c|c|c|c|}
\hline \multirow{2}{*}{$\begin{array}{l}\text { Sample sites latitude/ } \\
\text { longitude (UTM) }\end{array}$} & $\mathrm{Na}$ & $\mathrm{Ca}$ & $M g$ & K & $H+A l$ & $A l$ & $S$ & \multirow{2}{*}{$\begin{array}{c}\text { Corg } \\
\%\end{array}$} & $P$ & K & $\mathrm{Fe}$ & $\mathrm{Cu}$ & $Z n$ & $M n$ & $P b$ & \multirow{2}{*}{$\begin{array}{c}\text { pHwater } \\
1: 2.5\end{array}$} \\
\hline & \multicolumn{7}{|c|}{$\mathrm{Cmol}_{c} d m^{-3}$} & & \multicolumn{7}{|c|}{$m g l^{-1}$} & \\
\hline $\begin{array}{l}\text { Ipanema (I) E: 426.570/ } \\
\mathrm{N}: 3.116 .513\end{array}$ & 0.738 & 11 & 6 & 0.023 & 11 & 0 & 17761 & 5.11 & 786 & 9 & 25999 & 157.6 & 258,8 & 424.7 & 23.48 & 5.7 \\
\hline $\begin{array}{l}\text { Quimica (Q) E: } 427.335 / \\
\text { N: } 3.115 .506\end{array}$ & 0.308 & 9.4 & 5.6 & 0.328 & 1.3 & 0 & 15636 & 2.28 & 620 & 128 & 21542 & 71.78 & 35,38 & 337.7 & 10.83 & 6.6 \\
\hline $\begin{array}{l}\text { Arctowski (A) E: } \\
423.807 / \mathrm{N}: 3.106 .863\end{array}$ & 0.493 & 12 & 7 & 0.023 & 20 & 3.55 & 19516 & 0.97 & 1005 & 9 & 30833 & 42.98 & 82,38 & 582.7 & 37.68 & 4.3 \\
\hline
\end{tabular}


Technologies, Coralville, IA, USA), $1.8 \mathrm{mM} \mathrm{MgCl}_{2}$, $0.2 \mathrm{M}$ dNTPs, $1.5 \times$ bovine serum albumin (New England Biolabs, Ipswich, MA, USA), $1 \mathrm{U}$ of FastStart high-fidelity PCR system enzyme blend (Roche Applied Science, Indianapolis, IN, USA) and $10 \mathrm{ng}$ of the DNA template. The PCR program consisted of a $3 \mathrm{~min}$ initial denaturation at $95^{\circ} \mathrm{C} ; 30$ cycles of $95{ }^{\circ} \mathrm{C}$ for $45 \mathrm{~s}, 57^{\circ} \mathrm{C}$ for $45 \mathrm{~s}$ and $72{ }^{\circ} \mathrm{C}$ for $1 \mathrm{~min}$; and a 4-min final extension at $72^{\circ} \mathrm{C}$. For each sample, amplicons of three replicate PCRs were recovered using a QIAquick gel extraction kit followed by a QIAquick PCR purification kit (Qiagen, Germantown, MD, USA). Equimolar amplicons were combined and submitted to pyrosequencing using a Genome Sequencer FLX system (454; Life Sciences, Branford, CT, USA) at the Michigan State University Genomics Technology Support Facility. Sequences were excluded from the analysis if the read length was less than $150 \mathrm{bp}$ or if the primer sequences contained errors. Raw sequences were processed through the Ribosomal Database Project (RDP) pyrosequencing pipeline (http://wildpigeon.cme. msu.edu/pyro/index.jsp). Qualified sequences were clustered into operational taxonomic units (OTUs) defined by a $3 \%$ distance level using completelinkage clustering and were assigned to phyla by the RDP-II classifier using a 50\% confidence threshold (Wang et al., 2007). The sequences obtained in this study were uploaded and available at the GenBank under accessions numbers GU018184-GU020559, GU020561-GU021957, GU021959-GU022991, GU022993GU025964, GU025966-GU028543, GU028545-GU034810, GU034812-GU035406, GU035408-GU035688, GU035690GU035798, GU035800-GU036160, GU036162-GU036668, GU036670-GU037879, GU037881-GU037983, GU037985GU039799, GU039801-GU040384, GU040386-GU041302, GU041304-GU042193, GU042195-GU042423 and GU042425-GU0452689. Sequences that could not be classified into a phylum at this level of confidence were excluded from subsequent phylum composition analyses.

\section{Statistical analyses}

A total of 27088 partial 16S rRNA sequences were obtained from the 10 soil samples. The phylum composition was determined by taxonomic assignment performed by Classifier (Wang et al., 2007) with default parameters through the RDP II website. Multiple sequence alignments for each sample were made with ClustalX (with the default parameters). On the basis of the alignment, we constructed a distance matrix using DNAdist from the PHYLIP 3.6 package (Felsenstein, 2005) with the default parameters using the Jukes-Cantor model option (Jukes and Cantor, 1969). These pairwise distances served as inputs for DOTUR (Schloss and Handelsman, 2005) for clustering the sequences into OTUs. The clusters were constructed at a $3 \%$ dissimilarity cutoff and served as OTUs for generating predictive rarefaction models and for making calculations with the richness indices Ace and Chao1 (Chao and Bunge, 2002) and Shannon's diversity index (Shannon and Weaver, 1949). Fast UniFrac (Hamady et al., 2010) analyses were performed to compare the libraries based on other phylogenetic information. The Greengenes core set (May 2009) was used as the source of the reference sequences and the reference tree for a Megablast search and phylogenetic distribution, respectively. The Cluster Samples option was used to perform hierarchical clustering analysis using the weighted algorithm (that considers relative abundance information) and the normalization step. The $P$ Test option was used to test whether each pair of samples was significantly different. The $P$ Test significance ( $P$-values) for each pair of samples comparisons was obtained using 1000 permutations and the correction for multiple comparisons (Bonferroni correction).

\section{Results}

Community structure in the rhizosphere of vascular plants

PCR/DGGE analyses of 16S rRNA gene profiles were conducted to obtain an overview of the bacterial community structure in the rhizosphere across 14 samples. Samples were collected in triplicate from all sites except duplicate $D$. antarctica samples from point A, and many of the rhizosphere samples showed similar banding patterns. Community composition was determined by image analyses of the $16 \mathrm{~S}$ rRNA band profiles. Calculation of differences in the bacterial community composition based on these band patterns using the Pearson's correlation index (Figure 2a) showed no clear cluster formation even for different sample sites or for plant species, and more than $90 \%$ of similarity between all samples. The $16 \mathrm{~S}$ rRNA library obtained by pyrosequencing was analyzed by Fast UniFrac. No clustering groups based on plant species or sample site were observed (Figure 2b).

We detected more than 2000 bacterial sequences per sample, and 552-732 OTUs (3\% difference) were associated with the rhizosphere of each Antarctic vascular plant (Figure 3). Rarefactions curves calculated with DOTUR showed a similar pattern for all samples except for the QD7 sample. According to Figure 3 and to the OTU richness estimated by ACE (Table 3), this sample is more diverse than the other samples.

\section{Bacterial community composition and phylum-plant} associations

We examined the bacterial community compositions of five paired samples (samples collected at the same coordinates) of two vascular plant rhizospheres from three sites at Admiralty bay, King George Island, Maritime Antarctica. The relative abundances of the phyla detected are presented in Figure 4. Detailed phylogenetic analyses grouped 


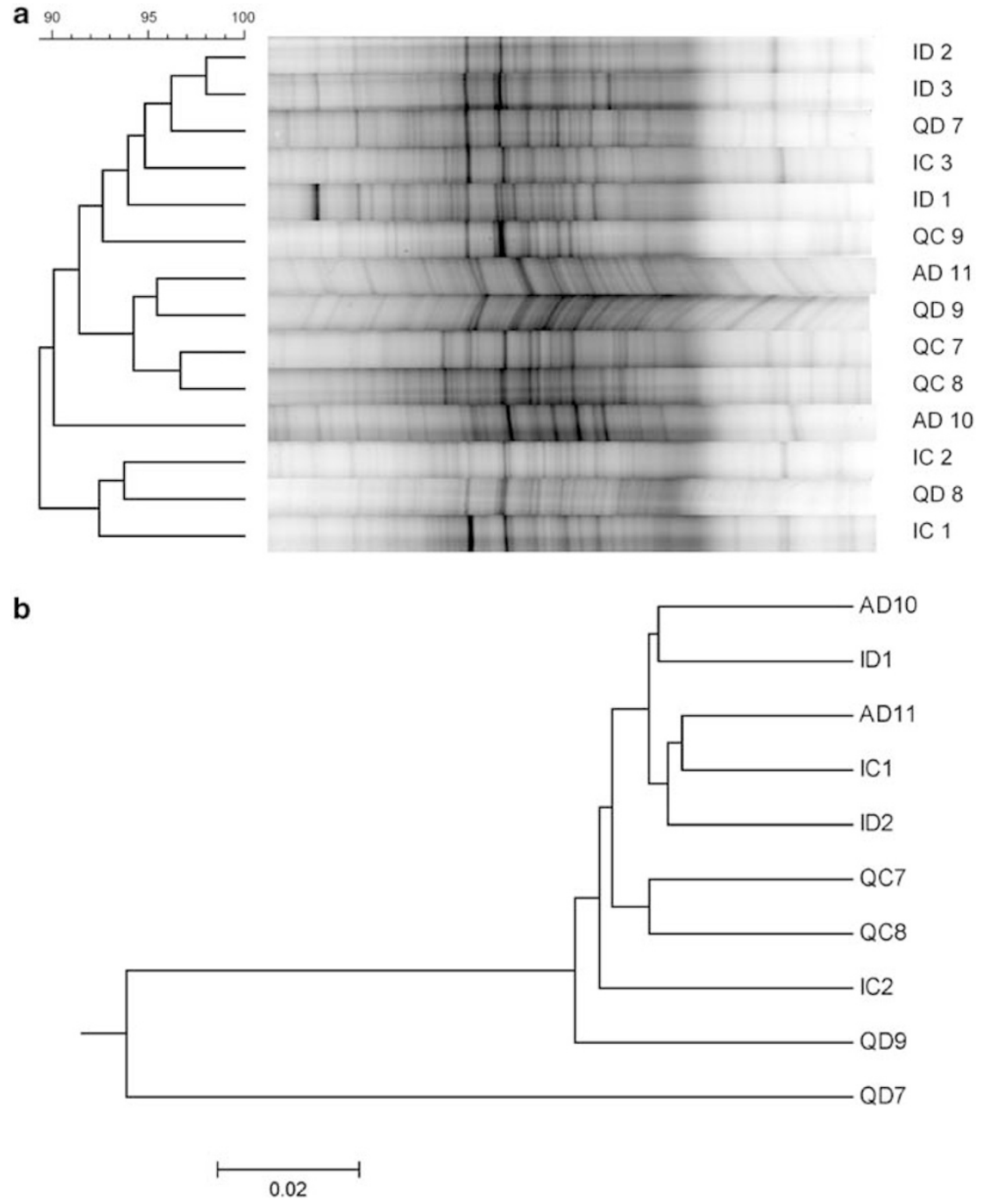

Figure 2 Cluster analyses of the rhizosphere bacterial communities. (a) Dendrogram analyses of bacterial denaturing gradient gel electrophoresis (DGGE) profiles of D. antarctica (D) and C. quitensis (C) rhizospheres from three sites, Arctowski (A); Ipanema (I); Quimica (Q), at Admiralty Bay using Pearson's correlations. The first letter in the code represents the sample site and the second letter in the code represents the plant species. Numbers distinguish the triplicate samples. (b) A dendrogram generated by Fast UniFrac Cluster Samples Analysis. For comparison of the ten 16S rRNA libraries, a weighted algorithm with normalized values was used.

the rhizosphere-associated bacterial sequences into 21 phyla, of which 14 phyla were abundant enough (more than $0.5 \%$ ) to be visible in the bars.

Most (92\%) of the bacterial rhizosphere sequences belonged to the nine phyla that are most often encountered in soil all over the world (Proteobacteria, Actinobacteria, Acidobacteria, Chloroflexi, Verrucomicrobia, Bacteroidetes, Planctomycetes, Gemmatimonadetes and Firmicutes) as described by Janssen (2006). However, the phylum distribution had a peculiar pattern. Firmicutes was the most abundant phylum in all the analyzed samples except for sample QD7, in which Proteobacteria was the most abundant phylum. The relative abundances of the phyla Actinobacteria and Proteobacteria varied among the samples, and together with Firmicutes, these phyla were the three most abundant phyla in all the analyzed samples.
To gain more insight into potential effects of plant species on rhizosphere bacteria, we also used phylumspecific sequence analyses to compare different sample sites about the presence of Firmicutes, Proteobacteria and Actinobacteria (Figure 5). These phyla were chosen due to their prevalence in all the analyzed samples. The Proteobacteria class distribution was highly similar in all studied samples from the Ipanema and Arctowski sites (Figure 5b). The Quimica samples had variations in the Proteobacteria classes. For the other predominate phyla, Actinobacteria and Firmicutes, no differences were observed, even when classes or orders (Figures 5a, $\mathrm{C}$ and d) were analyzed. Analysis of the orders present showed that Bifidobacteriales and Clostridiales in the Actinobacteria and Firmicutes phyla, respectively, were the most dominant in all the samples. 
The Clostridia class represented more than $70 \%$ of all Firmicutes sequences obtained in the analyzed samples, which indicates a high frequency of anaerobic bacteria in these samples. Bacilli represented about $15 \%$ of all Firmicutes sequences (Figure 5a).

The Proteobacteria phylum was represented by bacteria belonging to the classes Epsilonproteobacteria, Alphaproteobacteria, Gammaproteobacteria, Betaproteobacteria and Deltaproteobacteria. The most abundant classes in all samples were Gammaproteobacteria and Alphaproteobacteria, followed by Epsilonproteobacteria and Betaproteobacteria (Figure 5b).

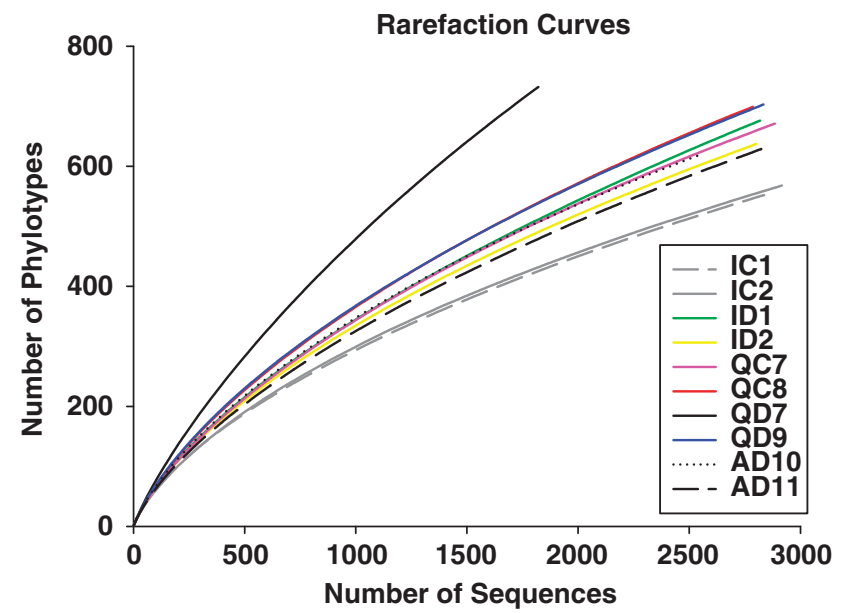

Figure 3 Rarefaction curves of partial sequences of bacterial 16S rRNA genes from the rhizosphere of the Antarctic species $D$. antarctica (D) and C. quitensis (C) inhabiting different sites, Arctowski (A); Ipanema (I); Quimica (Q), at Admiralty Bay, calculated by DOTUR with a $3 \%$ distance cutoff. The first letter in the code represents the sample site and the second letter in the code represents the plant species. Numbers distinguish the duplicate samples.
Analysis of the Actinobacteria phylum revealed dominance of the order Bifidobacteriales (Figure 5c).

Analyzing all the sample libraries together, we found the predominant genera Bifidobacterium (phylum Actinobacteria), Arcobacter (phylum Proteobacteria) and Faecalibacterium (phylum Firmicutes). Generally, only minor differences were observed in the bacterial rhizosphere communities isolated from different plant species or sample sites. A $P$ Test significance analysis and principal coordinate analysis of the Fast UniFrac metric matrix were used to compare the bacterial communities based on phylogenetic information, and this revealed that sample QD7 was significantly different from all the other samples (Table 4).

\section{Discussion}

The pyrosequencing method is able to identify a greater number of bacterial sequences than traditional DNA approaches, providing a more in-depth comparison of soil bacterial diversity (Wommack et al., 2008). The phylum-level diversity in Antarctic vascular plant rhizospheres is much higher than in previously reported data sets (Yergeau et al., 2007).

We observed that the bacterial community structure was very similar between almost all samples, unlike typical soil communities, despite the differences in soil composition shown in Table 2, especially the variations in $\mathrm{pH}, \mathrm{K}, \mathrm{Al}$ and $\mathrm{P}$. Also, Simas et al. (2008) showed that in Keller Peninsula (where our sampling points $\mathrm{I}$ and $\mathrm{Q}$ are located) the $\mathrm{N}$ content was very low (being not detected) and in Rakusa point (where our sampling point $\mathrm{A}$ is located) the $\mathrm{N}$ content was $4.3 \pm 1.0 \mathrm{~g} \mathrm{~kg}^{-1}$.

The sequence analyses completed in this study revealed that the phyla Firmicutes and Actinobacteria represent more than $70 \%$ of the sequences

Table 3 Estimated OTU richness, diversity indices and estimated sample coverage for 16S rRNA libraries of Antarctic soil samples

\begin{tabular}{|c|c|c|c|c|c|c|}
\hline \multirow[t]{2}{*}{ Library } & \multirow[t]{2}{*}{$N S$} & \multirow[t]{2}{*}{$O T U_{s}{ }^{\mathrm{a}}$} & \multicolumn{2}{|c|}{ Estimated OTU richness } & \multirow[t]{2}{*}{ Shannon $^{\mathrm{b}}$} & \multirow[t]{2}{*}{$E S C^{\mathrm{c}}$} \\
\hline & & & $A C E$ & Chao1 & & \\
\hline IC1 & 2837 & 552 & $1213(1065 ; 1405)$ & $1076(937 ; 1265)$ & $4.92(4.86 ; 4.99)$ & 0.89 \\
\hline IC2 & 2918 & 568 & $1218(1075 ; 1402)$ & $1187(1021 ; 1414)$ & $4.87(4.80 ; 4.94)$ & 0.89 \\
\hline ID1 & 2819 & 676 & $1767(1634 ; 1917)$ & $1510(1309 ; 1775)$ & $5.14(5.07 ; 5.21)$ & 0.85 \\
\hline ID2 & 2801 & 637 & $1452(1278 ; 1672)$ & $1335(1160 ; 1568)$ & $5.05(4.98 ; 5.12)$ & 0.87 \\
\hline QC7 & 2885 & 671 & $1463(1295 ; 1676)$ & $1365(1196 ; 1589)$ & $5.10(5.02 ; 5.16)$ & 0.86 \\
\hline QC8 & 2786 & 699 & $1585(1483 ; 1701)$ & $1420(1248 ; 1646)$ & $5.27(5.20 ; 5.34)$ & 0.85 \\
\hline QD7 & 1821 & 732 & $2047(1777 ; 2388)$ & $1695(1478 ; 1974)$ & $5.71(5.63 ; 5.79)$ & 0.73 \\
\hline QD99 & 2834 & 703 & $1624(1511 ; 1751)$ & $1460(1278 ; 1698)$ & $5.33(5.26 ; 5.39)$ & 0.85 \\
\hline$\widehat{A D} 10$ & 2561 & 621 & $1332(1180 ; 1527)$ & $1251(1091 ; 1465)$ & $5.14(5.07 ; 5.22)$ & 0.86 \\
\hline AD11 & 2826 & 629 & $1500(1313 ; 1738)$ & $1328(1154 ; 1560)$ & $4.98(4.91 ; 5.06)$ & 0.87 \\
\hline Total & 27088 & & & & & \\
\hline
\end{tabular}

Abbreviations: ESC, estimated sample coverage; NS, number of sequences for each library; OUT, operational taxonomic unit.

${ }^{a}$ Calculated with DOTUR at the $3 \%$ distance level.

bhannon diversity index calculated using DOTUR (3\% distance).

${ }^{\mathrm{c}} \mathrm{ESC}$ : $\mathrm{Cx}=1-(\mathrm{Nx} / n)$, where $\mathrm{Nx}$ is the number of unique sequences and $n$ is the total number of sequences.

Values in brackets are $95 \%$ confidence intervals as calculated by DOTUR. 


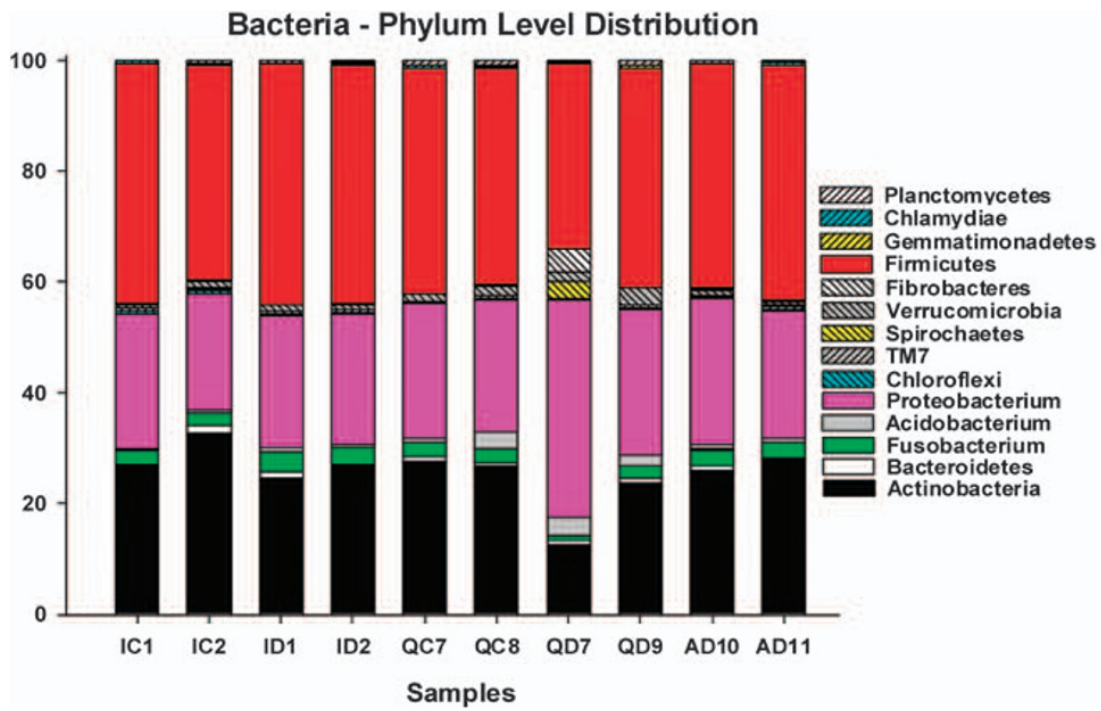

Figure 4 Distribution of partial sequences of bacterial 16S rRNA genes from the rhizosphere of the Antarctic species D. antarctica (D) and C. quitensis (C) inhabiting different sites, Arctowski (A); Ipanema (I); Quimica (Q), at Admiralty Bay classified using Ribosomal Database Project (RDP) Classifier at the phylum level. The first letter in the code represents sample site and the second letter in the code represents the plant species. Proportions were calculated based on sequences classified at the phylum level using RDP Classifier with a threshold level of $50 \%$.
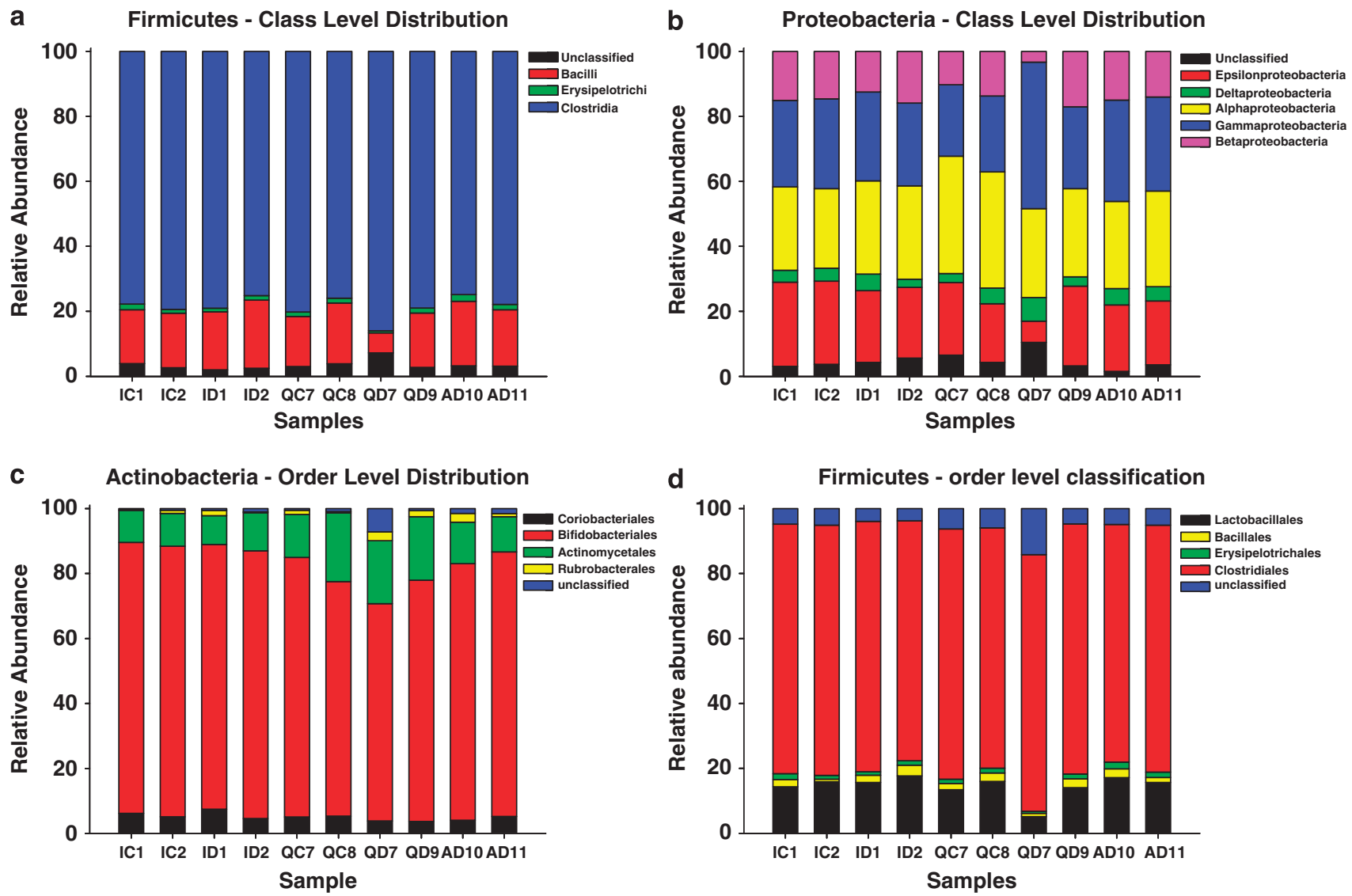

Figure 5 Composition of different phyla based on classification of partial 16S rRNA sequences of bacteria from the rhizosphere of the Antarctic species D. antarctica (D) and C. quitensis (C) inhabiting different sites, Arctowski (A); Ipanema (I); Quimica (Q), at Admiralty Bay using RDP Classifier: Firmicutes classes (a), Proteobacteria classes (b), Actinobacteria orders (c) and Firmicutes orders (d). The first letter in the code represents the sample site and the second letter in the code represents the plant species. 
Table 4 Statistic significance ( $P$-values) of differences among the bacterial communities of Antarctic soils calculated based on partial sequences of $16 \mathrm{~S}$ rRNA

\begin{tabular}{|c|c|c|c|c|c|c|c|c|c|c|}
\hline & $A D 10$ & $A D 11$ & $I C 1$ & IC2 & $I D 1$ & ID2 & $Q C 7$ & $Q C 8$ & $Q D 7$ & $Q D 9$ \\
\hline AD10 & - & 1.0 & 0.36 & 1.0 & 1.0 & 1.0 & 1.0 & 1.0 & $<\mathbf{0 . 0 0 1}$ & 0.09 \\
\hline AD11 & & - & 0.675 & 1.0 & 0.18 & 1.0 & 1.0 & $<\mathbf{0 . 0 0 1}$ & $<\mathbf{0 . 0 0 1}$ & 0.585 \\
\hline IC1 & & & - & 0.945 & 0.09 & 1.0 & 1.0 & $<\mathbf{0 . 0 0 1}$ & $<\mathbf{0 . 0 0 1}$ & 0.135 \\
\hline IC2 & & & & - & 1.0 & 1.0 & 1.0 & 0.495 & $<\mathbf{0 . 0 0 1}$ & 1.0 \\
\hline ID1 & & & & & - & 1.0 & 1.0 & $<\mathbf{0 . 0 0 1}$ & $<\mathbf{0 . 0 0 1}$ & 1.0 \\
\hline ID2 & & & & & & - & 1.0 & 1.0 & $<\mathbf{0 . 0 0 1}$ & 0.585 \\
\hline QC7 & & & & & & & - & 0.9 & $<\mathbf{0 . 0 0 1}$ & 1.0 \\
\hline QC8 & & & & & & & & - & $<\mathbf{0 . 0 0 1}$ & 1.0 \\
\hline QD7 & & & & & & & & & - & $<0.001$ \\
\hline QD9 & & & & & & & & & & - \\
\hline
\end{tabular}

$P$-values of UniFrac $P$ Test are calculated based on 1000 permutations (pairwise differences).

Bold values indicate the significantly different populations $(P<0.01)$.

in the 16S rRNA libraries generated by pyrosequencing. Both phyla are composed of spore forming groups such as Bacilli, Clostridia and Actinobacteria. One of the primary functions of spores is to ensure the survival of bacteria through periods of environmental stress, such as the extremely variable conditions in the Antarctic soil. Aislabie et al. (2009) also found that clones from Cape Hallet soils (Ross sea region) belonging to the Firmicutes phylum were most closely related to endospore formers. Yergeau et al. (2009) also detected, by PhyloChip, that some phyla (as Firmicutes) showed relatively higher presence at some sites (Fossil Bluff and Coal Nunatak) in maritime Antarctica.

Within the Firmicutes phylum, which was the most dominant phylum in almost all of the samples, we found that about $70 \%$ of the sequences belong to the Clostridia class. The high number of Clostridia suggests that anaerobic bacteria are abundant in Antarctic maritime vascular plant rhizospheres, which is the usual pattern found in temperate and tropical soils. However, the most common phylum in soils worldwide is Proteobacteria, even when the diversity is analyzed by a wide range of techniques (clone libraries, pyrosequencing and microarrays) (Janssen, 2006; Spain et al., 2009). Despite the fact that we also found a great abundance of Proteobacteria sequences, which represented $24.8 \%$ to almost $40 \%$ of all sequences found in the Antarctic rhizosphere samples (depending on the sample), this was not the dominant phylum. This singular microbiological profile of maritime Antarctica soils may be related to the unique soil properties of this environment when compared with those from other Antarctic climatic zones as revealed by Simas et al. (2008).

It is interesting to report that, although PCR/DGGE clustered sample QD7 near to the other rhizosphere samples, pyrosequencing revealed that this sample, which was collected at the sampling site closest to the Brazilian station (EACF) and was consequently the closest to human presence, presented some differences when compared with the other samples.
The differences between QD7 clustering depending on the method could be related to the greater effectiveness of pyrosequencing when compared to DGGE, especially because the PCR/DGGE data were not used for relative abundance analyses, just species richness and similarity, whereas the UniFrac analysis did include the relative abundance of OTUs (weighted). At this point, in QD7 the most abundant phylum recovered was Proteobacteria and not Firmicutes as observed in all other samples. Even though QD7 was the sample with the lowest number of sequences recovered, a similar diversity profile was observed when we standardized the size of the sample (that is, we used the same number of sequences for all samples; Supplementary Figure 1; Supplementary Table 1). In fact, when this type of normalization was performed, the difference between the QD7 sample and the other samples increased according to the CHAO1 index.

Previous reports described the presence of pollutants such as aromatic hydrocarbons and fecal sterols from wastewater discharge in the vicinity of the Brazilian station (Bícego et al., 1996; Martins et al., 2005; Luz et al., 2006; Oliveira et al., 2007). Thus, these anthropogenic impacts could be promoting these changes in microbial diversity, causing the pristine singular microbial diversity of the surrounding area to become more similar to the common profile that is frequently observed worldwide. However, we also must point out that this variation could be related to many other factors, such as soil composition at this exact point (for example, water and nutrient availability), animal influences (for example, mammal droppings) and biases in the methodological procedures. Because the communities associated with the other samples from this site (QD9) and the other vascular plants (QC7, QC8) do not share this divergence in composition, we consider this sample as an outlier. It would be necessary to evaluate a larger number of rhizosphere samples and chemical soil contents for a firm conclusion about these changes in the QD7 sample. 
The phylum distribution we found in the bacterial communities associated with the rhizospheres of Antarctic vascular plants was different not only from the phylum distribution of soils from other locations but also from Antarctic soil. Yergeau et al. (2007) studied bacterial communities across a latitudinal gradient in the maritime Antarctica and also found that Proteobacteria was the prevalent phylum in their 16S rRNA clone libraries. Actinobacteria was also abundant, but Firmicutes was not frequently detected. The differences from our study results could be related to the locations of the sampling points. Also, the sensitivity can be lower in clone libraries than in pyrosequencing, especially to detect more rare taxa. In cold desert mineral soils in the Antarctic Dry Valley, 16S rRNA clone libraries showed that Cyanobacteria, Actinobacteria, Acidobacteria and Bacteroidetes were the most prevalent phyla in three samples (Smith et al., 2006). Janssen (2006) also reported that Proteobacteria, Acidobacteria and Actinobacteria are often the most abundant phyla in soils, and emphasized that members of Bacteroidetes and Firmicutes are generally less abundant, in contrast with our study results.

Fulthorpe et al. (2008) showed by pyrosequencing that Chitinophaga, Acidobacterium and Acidovorax were the dominant genera in soils from Florida (USA), Illinois (USA), Brazil and Canada. The results of our study also showed different patterns at the genus level in Antarctic rhizospheres, with Bifidobacterium, Ruminococcus and Faecalibacterium being the most abundant genera. Such peculiar diversity in rhizosphere soils from the maritime Antarctica, and the predominance of spore-forming and anaerobic bacteria, could be explained by another peculiarity of the environmental conditions of the Antarctic. Spores ensure the survival of bacteria through periods of harsh conditions, and during the spore stage, bacterial metabolism is very slow (Singh et al., 2007). In the rhizosphere, carbon sources are more available, but in Antarctic rhizospheres, this availability could be greatly reduced, especially during the winter. Because Firmicutes encompasses several spore-forming genera, it is highly plausible that the environment is selecting a very restrictive group that is able to survive in severe conditions for long periods of time. Also, according to Ramsay (1983), there are high levels of moisture in marine-influenced soils of Antarctica, which range from $6 \%$ to $43 \%$ water, and this could be a promoter of anaerobic conditions.

We hypothesized that in addition to all the abiotic conditions, which are the main promoters of Antarctic terrestrial environments (Hogg et al., 2006), intense sea bird activity on ice-free areas along the Antarctic coast leads to the formation of so-called ornithogenic soils (Campbell and Claridge, 1987; Simas et al., 2007), and this could also be related to the predominance of Firmicutes. Ornithogenic soil, a particular type of cryogenic soil, occurs at active or abandoned penguin rookeries. Organic matter is brought to the rookery during the summer when the penguins are ashore, and organic matter is added to the soil in the form of penguin guano, feathers, eggshells and bird remains (Aislabie et al., 2009). Guano accumulation in penguin rookeries represents the most abundant source of organic matter in the Antarctic terrestrial ecosystem (Simas et al., 2007). This same guano could be a source of Firmicutes and other phyla that are associated with the penguin gut, as some authors reported that Firmicutes is the most abundant phylum observed in penguin fecal flora (Banks et al., 2009) and in soils with a penguin presence (Aislabie et al., 2009). The sequencing of bulk soils samples will be the next step to corroborate the results obtained from these rhizosphere samples and to determine the selective pressure of Antarctic conditions as well as the penguin influence on bacterial community structure of Antarctic soils from Admiralty bay.

We first expected that the two plant species would have at least a small influence on the selection of specific bacterial communities, but we observed that the bacterial community structure was very similar in microbial diversity (species richness) and composition (who is there and relatively how many) between all samples taken from different locations. This is in direct contradiction with the hypothesis that there would be differences between the rhizosphere communities of different plants. An interpretation that should be considered is that there are other more powerful environmental influences that result in the observed bacterial community structure (that is, moisture content and freeze-thaw cycles).

The presence of dense vegetation has been suggested to be able to reduce the severity of the Antarctic on soil microhabitats by providing enhanced moisture and thermal retention compared with bulk soils (Simas et al., 2007). The influence of cover vegetation on the soil microbial community is an issue of great discussion between scientists elsewhere. Several authors have proposed that vascular plants, and to a lesser extent bryophytes, are key promoters in the selection of specific microbial communities inhabiting the soil (Smalla et al., 2001; Kowalchuk et al., 2002), although some authors have stated that soil characteristics could be the major factors that determine rhizosphere microbial populations in areas populated by certain kinds of plants, for example, different grass species (Singh et al., 2007). Other authors have observed that soil characteristics can be more relevant to microbial diversity than the rhizosphere effect (Groffman et al., 1996; Jonhson et al., 2003; Garbeva et al., 2004). Buyer et al. (1999) also failed to observe differences among the microbial communities from rhizospheres from different plant species growing in the same soil. Kielak et al. (2008) observed that differences in vegetation composition and plant species led to only minor changes in soil microbial communities in a former arable field. The authors suggested that this result could be because some 
soils may be less predisposed to revealing rhizosphere effects.

Garbeva et al. (2004) proposed that the complexity of the microbial interactions in the soil, including interactions between microorganisms and soil and between microorganisms and plants, are more likely to explain microbial diversity tendencies. On the basis of our study data, we found that other factors, such as environmental conditions and sea bird influences, also seem to be essential to microbial adaptation, and consequently they shape the local microbial diversity. Yergeau et al. (2007) suggested that bacterial abundance and community structure could be influenced both by plant and weather factors, with abundant and complex interactions among these variables.

According to the analysis of all the data obtained in this study, we detected bacterial diversity that was different from that already described for maritime Antarctica soils without cover plants. However, studies on the role of this large bacterial community in biogeochemical cycles are necessary to determine which of these microorganisms are really active in this extreme environment. In a recent report, Hopkins et al. (2009) described evidence of a contribution of microorganisms to organic carbon turnover in the soil in Antarctic dry valleys, which make up one of the most environmentally harsh terrestrial ecosystems. Such information is essential to help us predict the possible consequences of microbial disturbances and their consequent impacts on biogeochemical transformations in Antarctic ecosystems.

The increase in temperature detected in the past 50 years in maritime Antarctica will extend the length of the warm season and therefore may expand the ice-free areas in this region. A considerable increase in the number of both $D$. Antarctica and C. quitensis colonies in the western Antarctic Peninsula has been already reported, which seems to be a response to the increasing summer air temperatures (Convey and Smith, 2006). The soil bacterial community may change as less extreme weather conditions promote the activation of sporeforming cells. Greater biological activity in the soil could make it more susceptible to the establishment of invasive species. However, existing studies to date about the Antarctic microbiota are still not sufficient to predict the consequences of global changes, including warming, for this environment.

One of the major contributions of this work is an increase in the knowledge about the peculiar microbial diversity of the rhizospheres of Antarctic vascular plants, especially new data about the great abundance of anaerobes in this environment. Allison and Martiny (2008) discussed resistance, resilience and redundancy in microbial communities. They observed that many authors showed that changes in the composition of microbial communities are often associated with changes in the process rates of ecosystems. Bardgett et al. (2008) discussed microbial contributions to climate change through carbon cycle feedbacks, and proposed that very little is known about the effects of multiple interacting climate promoters on soil microbes and their contribution to climate change. Pointing et al. (2009) described the highly specialized bacterial communities encountered in the Dry Valleys and discussed the unpredictable sensitivity of these communities to climate changes. These authors emphasized the urgency of documenting the diversity of the Dry Valley biome, and we believe that this should also include documenting maritime Antarctica diversity.

Thus, the remaining questions are as follows: could human impacts and global warming affect the abundance of anaerobic representatives in the Antarctic microbial communities described in this paper? How could these effects influence microbial function and equilibrium in Antarctic? Perhaps the use of these molecular tools and others (for example, quantitative PCR and stable isotope probing will allow us to clarify and establish connections between microbial diversity and ecosystem function.

\section{Acknowledgements}

This study received financial and logistic support from the Brazilian Antarctic Program, PROANTAR, as part of the IPY Activity no. 403 'MIDIAPI Microbial Diversity of Terrestrial and Maritime ecosystems in Antarctic Peninsula' (520194/2006-3) and FAPERJ. We thank Prof Andrew Macrae (IMPPG/UFRJ) for critical review of this paper.

\section{References}

Acosta-Martinez V, Dowd S, Sun Y, Allen V. (2008). Tagencoded pyrosequencing analysis of bacterial diversity in a single soil type as affected by management and land use. Soil Biol Biochem 40: 2762-2770.

Aislabie J, Jordan S, Ayton J, Klassen JL, Barker GM, Turner S. (2009). Bacterial diversity associated with ornithogenic soil of the Ross Sea region, Antarctica. Can J Microbiol 55: 21-36.

Allison SD, Martiny JBH. (2008). Resistance, resilience and redundancy in microbial communities. Proc Natl Acad Sci USA 105: 11512-11519.

Banks S, Cary C, Hogg ID. (2009). The phylogeography of Adelie penguin faecal flora Environ. Microbiology 11: $577-588$

Bardgett RD, Freeman C, Ostle NJ. (2008). Microbial contributions to climate change through carbon cycle feedbacks. ISME J 2: 805-814.

Beyer L. (2000). Properties, formation and geo-ecological significance of organic soils in the coastal region of East Antarctica. Catena 39: 79-83.

Bícego MC, Weber RR, Ito RG. (1996). Aromatic hydrocarbons on surface waters of Almiratly bay, King George Island, Antarctica. Mar Pollut Bull 32: 549-553. 
Binladen J, Gilbert MT, Bollback JP, Panitz F, Bendixen C, Nielsen R et al. (2007). The use of coded PCR primers enables high-throughput sequencing of multiple homolog amplification products by 454 parallel sequencing. PLoS One 2: e197.

Buyer JS, Roberts DP, Russek-Cohen E. (1999). Microbial community structure and function in the spermosphere as affected by soil and seed type. Can J Microbiol 45: 138-144.

Campbell IB, Claridge GGC. (1987). Antarctica: Soils, Weathering Processes and Environment, (Developments in Soil Science 16). Elsevier: Amsterdam, the Netherlands.

Chao A, Bunge J. (2002). Estimating the number of species in a stochastic abundance model. Biometrics 58: 531-539.

Convey P. (2001). Antarctic ecosystems. In: Levin SA (ed). Encyclopedia of Biodiversity. Academic Press: San Diego, pp 171-184.

Convey P, Smith RIL. (2006). Responses of terrestrial Antarctic ecosystems to climate change. Plant Ecol 182: 1-10.

Dowd SE, Sun Y, Wolcott RD, Domingo A, Carroll JA. (2008). Bacterial tag-encoded FLX amplicon pyrosequencing (bTEFAP) for microbiome studies: bacterial diversity in the ileum of newly weaned Salmonellainfected pigs. Foodborne Path Dis 5: 459-472.

EMBRAPA (1997). Manual de Métodos de Análise de Solo, 2nd edn. EMBRAPA-CNPS, Documentos: Rio de Janeiro, Brazil.

Felsenstein JP. (2005). (Phylogeny Inference Package) Version 36. Distributed by the author Department of Genome Sciences, University of Washington: Seattle.

Fulthorpe RR, Roesch LF, Riva A, Triplett EW. (2008). Distantly sampled soils carry few species in common. ISME J 2: 901-910.

Garbeva P, van Veen JA, van Elsas JD. (2004). Microbial diversity in soil: selection microbial populations by plant and soil type and implications for disease suppressiveness. Annu Rev Phytopathol 42: 243-270.

Groffman PM, Hanson CC, Kiviat E, Stevens G. (1996). Variation in microbial biomass and activity in four different wetland types. Soil Sci Soc Am J 60: $622-629$

Hamady M, Lozupone C, Knight R. (2010). Fast UniFrac: facilitating high-throughput phylogenetic analyses of microbial communities including analysis of pyrosequencing and PhyloChip data. ISME J 4: 17-27.

Heuer H, Krsek M, Baker P, Smalla K, Wellington EM. (1997). Analysis of actinomycete communities by specific amplification of genes encoding 16S rRNA and gel-electrophoretic separation in denaturing gradients. Appl Environ Microbiol 63: 3233-3241.

Hogg ID, Cary SC, Convey P, Newsham KK, G O’Donnell A, Adams BJ et al. (2006). Biotic interactions in Antarctic terrestrial ecosystems: are they a factor? Soil Biol Biochem 38: 3035-3040.

Hopkins DW, Sparrow AD, Gregorich EG, Elberling B, Novis P, Fraser F et al. (2009). Isotopic evidence for the provenance and turnover of organic carbon by soil microorganisms in the Antarctic dry valleys. Environ Microbiol 11: 597-608.

Janssen PH. (2006). Identifying the dominant soil bacterial taxa in libraries of $16 \mathrm{~S}$ rRNA and $16 \mathrm{~S}$ rRNA genes. Appl Environ Microbiol 72: 1719-1728.

Jonhson D, Booth RE, Whiteley AS, Bailey MJ, Read DJ, Grime JP et al. (2003). Plant community composition affects the biomass, activity and diversity of microorganisms in limestone grassland soil. Eur J Soil Sci 54: 671-677.

Jukes TH, Cantor CR. (1969). Evolution of protein molecules. In: Unro HNM (ed.). Mammalian Protein Metabolism. Academic Press: New York, pp 21-132.

Kielak A, Pijl AS, van Veen JA, Kowalchuk GA. (2008). Differences in vegetation composition and plant species identity lead to only minor changes in soilborne microbial communities in a former arable field. FEMS Microbiol Ecol 63: 372-382.

Kowalchuk GA, Buma DS, de Boer W, Klinkhamer PG, van Veen JA. (2002). Effects of above-ground plant species composition and diversity on the diversity of soilborne microorganisms. Antonie Van Leeuwenhoek 81: 509-520.

Luz AP, Ciapina EMP, Gamba RC, Lauretto MS, Farias EWC, Bicego MC et al. (2006). Potential for bioremediation of hydrocarbon polluted soils in maritime Antarctic. Antarct Sci 18: 335-343.

Martins CC, Montone RC, Gamba RC, Pellizari VH. (2005). Sterols and fecal indicator microorganisms in sediments from Admiralty Bay, Antarctica Brazil. J Oceanogr 53: 1-12.

Oliveira LM, Mendonça ES, Jham G, Schaefer CEGR, Silva IR, Albuquerque M. (2007). Hidrocarbonetos em solos e sedimentos do entorno da Estação Antártica Brasileira Comandante Ferraz. Oecol bras 11: 144-156.

Panikov NS. (1999). Understanding and prediction of soil microbial community dynamics under global change. Appl Soil Ecol 11: 161-176.

Peck LS, Clark MS, Clarke A, Cockell CS, Convey P, Detrich HW et al. (2005). Genomics: applications to Antarctic ecosystems. Polar Biol 28: 351-365.

Pointing SB, Chan Y, Lacap DC, Lau MC, Jurgens JA, Farrell RL. (2009). Highly specialized microbial diversity in hyper-arid polar desert. Proc Natl Acad Sci USA 106: 19964-19969.

Ramsay AJ. (1983). Bacterial biomass in ornithogenic soils of Antarctica. Polar Biol 1: 221-225.

Roesch LF, Fulthorpe RR, Riva A, Casella G, Hadwin AK, Kent AD et al. (2007). Pyrosequencing enumerates and contrasts soil microbial diversity. ISME J 1: 283-290.

Schloss PD, Handelsman J. (2005). Introducing DOTUR, a computer program for defining operational taxonomic units and estimating species richness. Appl Environ Microbiol 71: 1501-1506.

Shannon CE, Weaver W. (1949). The Mathematical Theory of Communications. University of Illinois Press: Urbana.

Simas FNB, Schaefer CEGR, Melo VF, Albuquerque-Filho MR, Michel RFM, Pereira VV et al. (2007). Ornithogenic cryosols from Maritime Antarctica: phosphatization as a soil forming process. Geoderma 138: 191-203.

Simas FNB, Schaefer CEGR, Albuquerque-Filho MR, Francelino MR, Filho EIF, Costa LM. (2008). Genesis, properties and classification of cryosols from Admiralty Bay, maritime Antarctica. Geoderma 144: 116-122.

Simões JC, Arigony Neto J, Bremer UF. (2004). O uso de mapas antárticos em publicações. Pesq Antart Brasil 4: 191-197.

Singh BK, Munro S, Potts JM, Millard P. (2007). Influence of grass species in soil type on rhizosphere microbial community structure in grassland soils. Appl Soil Ecol 36: $147-155$. 
Smalla K, Wieland G, Buchner A, Zock A, Parzy J, Kaiser S et al. (2001). Bulk and rhizosphere soil bacterial communities studied by denaturing gradient gel electrophoresis: plant-dependent enrichment and seasonal shifts revealed. Appl Environ Microbiol 67: 4742-4751.

Smith JJ, Tow LA, Stafford W, Cary C, Cowan DA. (2006). Bacterial diversity in three different Antarctic cold desert mineral soils. Microb Ecol 51: 413-421.

Sogin ML, Morrison HG, Huber JA, Mark Welch D, Huse SM, Neal PR et al. (2006). Microbial diversity in the deep sea and the underexplored 'rare biosphere'. Proc Natl Acad Sci USA 103: 12115-12120.

Spain AM, Krumholz LR, Elshahed MS. (2009). Abundance, composition, diversity and novelty of soil Proteobacteria. ISME J 3: 992-1000.

Vishniac HS. (1993). The microbiology of Antarctic soils. In: Friedmann EI (ed). Antarctic Microbiology. WileyLiss: New York, pp 279-341.

Wall DH, Virginia RA. (1999). How soils structure communities in the Antarctic dry valleys. Bioscience 49: 973-983.

Wang Q, Garrity GM, Tiedje JM, Cole JR. (2007). Naive Bayesian classifier for rapid assignment of
rRNA sequences into the new bacterial taxonomy. Appl Environ Microbiol 73: 5261-5267.

Wommack KE, Bhavsar J, Ravel J. (2008). Metagenomics: read length matters. Appl Environ Microbiol 74: 1453-1463.

Wynn-Williams DD. (1990). Microbial colonization processes in Antarctic fellfield soil-an experimental overview. Polar Biol 3: 164-178.

Wynn-Williams DD. (1996). Antarctic microbial diversity: the basis of polar ecosystem processes. Biodivers Conserv 5: 1271-1293.

Yergeau E, Kowalchuk GA. (2008). Responses of Antarctic soil microbial communities and associated functions to temperature and freeze-thaw cycle frequency. Environ Microbiol 10: 2223-2235.

Yergeau E, Newsham KK, Pearce DA, Kowalchuk GA. (2007). Patterns of bacterial diversity across a range of Antarctic terrestrial habitats. Environ Microbiol 9: 2670-2682.

Yergeau E, Schoondermark-Stolk SA, Brodie EL, Déjean S, DeSantis TZ, Gonçalves O et al. (2009). Environmental microarray analyses of Antarctic soil microbial communities. ISME J 3: 340-351.

Supplementary Information accompanies the paper on The ISME Journal website (http://www.nature.com/ismej) 